\title{
DENTAL CARIES IN AN ELDERLY POPULATION IN BRAZIL
}

\author{
Lilian Berta RIHS', Débora Dias da SILVA², Maria da Luz Rosário de SOUSA ${ }^{3}$
}

\author{
1- DDS, MSc, PhD student, Department of Community Dentistry, Dental School of Piracicaba, State University of Campinas,.Piracicaba, SP, Brazil. \\ 2- DDS, MSc, PhD in Community Dentistry, Department of Community Dentistry, Dental School of Piracicaba, State University of Campinas, Piracicaba, \\ SP, Brazil. \\ 3- DDS, MS, PhD, Full Professor, Department of Community Dentistry, Dental School of Piracicaba, State University of Campinas,.Piracicaba, SP, \\ Brazil.
}

Corresponding address: Lilian Berta Rihs - Rua Aquilino Pacheco, 1370, ap. 114 - Bairro Alto - 13419-150 Piracicaba, SP, Brasil - Phone: +55-193301-2220 - e-mail: lilianberta@yahoo.com.br

Received: January 16, 2008 - Modification: June 17, 2008 - Accepted: July 09, 2008

\begin{abstract}
$T_{\text {his }}$ $T_{\text {his study evaluated dental caries according to the presence of natural teeth and sociodemographic conditions of an elderly }}$ population in the state of São Paulo, Brazil. Examinations were performed according to the World Health Organization's guidelines. The sample of 1,192 elderly individuals aged 65 to 74 years was stratified according to the presence of teeth and the following variables: gender, race, age, city size and Human Development Index (HDI). The Mann Whitney and Kruskal Wallis tests were applied at a confidence level of $95 \%$ for analysis of results. In the total sample, $68.9 \%(\mathrm{n}=822)$ were edentulous; the mean of present teeth was 3.5 and the DMFT was 30.2, being 28.5 of missing teeth. Among dentate individuals $(n=370)$, the mean of present teeth was 11.3, the DMFT was 26.2 and the missing component accounted for 20.7 teeth. The differences observed in the evaluated conditions should be highlighted: the mean number of present teeth was higher among younger individuals (from 65 to 69 years) [12.1] and among those living in cities with high HDI [12.9]; the DMFT was lower among men [24.9] and non-Caucasians [25.1]. Based on these findings, it may be concluded that specific dental programs should be established, with emphasis on oral health promotion and dental caries control, as well as public health policies that may enhance the access to the services provided.
\end{abstract}

Key words: Oral health. Elderly. Dental caries. Tooth loss.

\section{INTRODUCTION}

Dental caries is still an important oral health problem in most industrialized countries, affecting most adults and having tooth loss as its main outcome ${ }^{13}$. In Brazil, the proportion of edentulous individuals older than 65 years is still high and may reflect the difficult access to dental services for a large portion of the population, or even the lack of importance assigned by these individuals to oral health along their lives. Conversely, international studies have shown that, when adequate attention is provided to elderly individuals, a larger number of natural teeth and lower DMFT are achieved ${ }^{8,10,23,24}$ and hence the number of missing teeth is reduced, which enhances the quality of life. However, some regions worldwide still present a high percentage of edentulism ${ }^{13,20}$.

Until 1998, no epidemiological studies involving adults older than 65 to 74 years had been conducted in Brazil, considering the country as a whole or its states. The existing results were restricted to some regions in which the oral conditions were associated with a high percentage of edentulism, high DMFT index (mean of decayed, missing and filled teeth) and need of prostheses ${ }^{1,2,6,12,14}$.

Thus, this study aimed to evaluate dental caries according to the presence of natural teeth and sociodemographic conditions of an elderly population in the state of São Paulo, in Southeast Brazil.

\section{MATERIAL AND METHODS}

This cross-sectional study was conducted in the state of São Paulo, Southeast Brazil. Twenty-nine cities were selected for inclusion in this study [for further information, please, refer to www.saude.sp.gov.br/saude_bucal/html/ saude_bucal_est_epide.html $]^{16}$. The sample size according to age and city size was calculated according to recommendations of the World Health Organization (WHO ${ }^{25}$ (1987).

This was the first investigation on elderly individuals addressing the entire state of São Paulo. This work was considered an exploratory study, in which the random sample included elderly individuals attending associations and participating in health programs to the elderly. The subjects were elderly individuals who attended a third age group, as well as users of public health services aged 65 to 74 years, who were examined at the environment where they were recruited. The elderly individuals were comfortably placed on a chair in 
front of the examiner, both sitting. Examinations were performed with the aid of dental mirrors and CPI "ball point" periodontal probes under natural light by 66 properly calibrated dentists. The dental caries experience was measured by the DMFT index according to criteria recommended by the $\mathrm{WHO}^{26}$ (1997), considering 32 teeth. In the calibration phase, the percentage of inter-examiner agreement was $84.5 \%$. Data were collected between August and December 1998, with a total number of 1,192 valid examinations.

For analysis of results, the sample was stratified in relation to the presence of teeth, in addition to sociodemographic variables such as gender, race (Caucasian and non-Caucasian), age (65-69 and 70-74 years), city size (small, medium, large) and HDI - a composite measurement summarizing information on income, educational level and longevity - where 19 cities presented medium HDI (0.645 to 0.799$)$ and 10 presented high HDI $(0.800 \text { to } 0.908)^{15}$. The Mann-Whitney and Kruskal-Wallis

TABLE 1- Sample distribution according to gender, race, age, city size and HDI. Southern Region of the state of São Paulo

\begin{tabular}{|c|c|c|}
\hline & $\begin{array}{c}\text { General } \\
\text { Sample } \\
\text { n (\%) }\end{array}$ & $\begin{array}{c}\text { Dentate } \\
\text { Individuals } \\
\mathrm{n}(\%)\end{array}$ \\
\hline \multicolumn{3}{|l|}{ Gender } \\
\hline Male & $437(36.7)$ & $163(44.1)$ \\
\hline Female & 755 (63.3) & 207 (55.9) \\
\hline \multicolumn{3}{|l|}{ Race } \\
\hline Caucasian & 871 (73.2) & 260 (71.3) \\
\hline Non-Caucasian & $321(26.8)$ & $110(29.7)$ \\
\hline \multicolumn{3}{|l|}{ Age } \\
\hline $65-69$ years & $697(58.5)$ & $251(67.8)$ \\
\hline $70-74$ years & $495(41.5)$ & 119 (32.2) \\
\hline \multicolumn{3}{|l|}{ City size } \\
\hline Small & $388(32.6)$ & $128(34.6)$ \\
\hline Medium & $360(30.2)$ & $97(26.2)$ \\
\hline Large & $444(37.2)$ & $145(39.2)$ \\
\hline \multicolumn{3}{|l|}{ HDI* $^{*}$} \\
\hline Medium & $546(45.8)$ & $176(476)$ \\
\hline High & $646(54.2)$ & $194(52.4)$ \\
\hline
\end{tabular}

HDI (Human Development Index): a composite measurement summarizing information on income, educational level and longevity. tests were applied at a confidence level of $5 \%(\mathrm{p}<0.05)$ for the analysis of results, considering that sample did not show a normal distribution.

Even though the data were secondary, the study was revised and approved by the Institutional Review Board of the Dental School of Piracicaba (protocol n. 017/2003).

\section{RESULTS}

\section{General sample and dentate individuals}

During data collection, the intra-examiner agreement was 98\%. A total of 1,192 elderly individuals were examined, being $36.7 \%(n=437)$ males and $63.3 \%(n=755)$ females. In this work, edentulous individuals corresponded to $68.9 \%(\mathrm{n}=822)$ and 370 individuals were dentate. The sample distribution for all examined individuals as well as for dentate individuals according to sociodemographic variables is presented in Table 1.

Table 2 presents data corresponding to the mean number of present teeth and the DMFT index and its components, both for the total examined population and for dentate individuals. Individuals presenting 20 or more teeth in this study accounted for $18.1 \%(n=67)$ of the entire sample.

\section{Sociodemographic variables}

The sociodemographic variables analyzed in this study included gender, race, age, number of inhabitants in the city, HDI and city size.

Table 3 shows the mean number of present teeth, as well as the caries experience according to gender, race, age and HDI. The males presented lower DMFT, higher mean of decayed teeth and fewer filled teeth. With regard to race, DMFT was the only variable presenting difference between groups, with higher DMFT for the Caucasians. Younger individuals (65-69 years) presented more teeth, more decayed teeth and fewer missing teeth. Individuals living in cities with high HDI presented higher mean of present teeth, more filled teeth and fewer decayed and missing teeth.

Table 4 shows the caries experience according to the city size. This table reveals differences between city size and the decayed and filled components. Elderly living in small cities presented more decayed teeth and fewer filled teeth. Table 5 presents data on the mean number of present teeth, DMFT

TABLE 2- Mean of present teeth and caries experience in all individuals and among dentate individuals. Southern Region of the state of São Paulo

\begin{tabular}{l|cc}
\hline Southeast region & $\begin{array}{c}\text { All individuals } \\
(\mathbf{n = 1 , 1 9 2 )}\end{array}$ & $\begin{array}{c}\text { Dentate individuals } \\
(\mathbf{n}=\mathbf{3 7 0})\end{array}$ \\
\hline Mean of present teeth & 3.5 & 11.3 \\
DMFT (Cl95\%) & $30.2(30.0-30.4)$ & $26.2(25.6-26.7)$ \\
Decayed (Cl95\%) & $0.5(0.4-0.7)$ & $1.8(1.4-2.1)$ \\
Missing (Cl95\%) & $28.5(26.3-27.6)$ & $20.7(19.9-21.4)$ \\
Filled $(\mathrm{Cl} 95 \%)$ & $1.2(1.0-1.4)$ & $3.7(3.2-4.3)$ \\
\hline
\end{tabular}


TABLE 4- Mean of present teeth and dental caries experience in dentate individuals according to city size. Southern Region of the state of São Paulo

\begin{tabular}{|c|c|c|c|c|}
\hline Variables & $\begin{array}{l}\text { Large } \\
(n=128)\end{array}$ & $\begin{array}{l}\text { Medium } \\
(\mathrm{n}=97)\end{array}$ & $\begin{array}{l}\text { Small } \\
(n=145)\end{array}$ & $\mathbf{p}$ \\
\hline Mean of present teeth (SD) & $11.6(7.5)$ & $11.7(7.1)$ & $10.7(8.0)$ & 0.24 \\
\hline DMFT (SD) & $26.4(5.1)$ & $26.6(5.3)$ & $25.5(6.1)$ & 0.66 \\
\hline Decayed (SD) & $1.2^{\mathrm{a}}(2.2)$ & $1.8^{\mathrm{a}}(3.6)$ & $2.4^{\mathrm{b}}(3.2)$ & $<0.001$ \\
\hline Filled (SD) & $4.8^{\mathrm{a}}(6.2)$ & $4.5^{\text {a }}(45.5)$ & $1.8^{\mathrm{b}}(3.9)$ & $<0.001$ \\
\hline Missing (SD) & $20.4(7.5)$ & $20.3(7.2)$ & $21.3(8.0)$ & 0.25 \\
\hline
\end{tabular}

Means followed by different letters in rows indicate statistically significant difference according to city size.

TABLE 3- Clinical variables in dentate individuals according to gender, race, and age. Southern Region of the state of São Paulo

\begin{tabular}{|c|c|c|c|c|c|c|c|c|c|c|c|c|}
\hline & \multicolumn{3}{|c|}{ GENDER } & \multicolumn{3}{|c|}{ RACE } & \multicolumn{3}{|c|}{ AGE } & \multicolumn{3}{|c|}{ HDI } \\
\hline & $\begin{array}{c}\text { Male } \\
(n=163)\end{array}$ & $\begin{array}{l}\text { Female } \\
(n=207)\end{array}$ & $p$ & $\begin{array}{c}\text { Caucasian } \\
(n=260)\end{array}$ & $\begin{array}{c}\text { Non- } \\
\text { Caucasian } \\
(n=110)\end{array}$ & $p$ & $\begin{array}{c}65-69 \\
\text { years } \\
(n=251)\end{array}$ & $\begin{array}{c}70-74 \\
\text { years } \\
(n=119)\end{array}$ & $p$ & $\begin{array}{l}\text { Medium } \\
(n=176)\end{array}$ & $\begin{array}{c}\text { High } \\
(n=194)\end{array}$ & $p$ \\
\hline $\begin{array}{c}\text { Mean of present } \\
\text { teeth (SD) }\end{array}$ & $\begin{array}{l}12.4 \\
(8.3)\end{array}$ & $\begin{array}{l}10.5 \\
(6,8)\end{array}$ & 0.05 & $\begin{array}{l}11.2 \\
(7.8)\end{array}$ & $\begin{array}{l}11.6 \\
(7.1)\end{array}$ & 0.32 & $\begin{array}{l}12.1 \\
(7.8)\end{array}$ & $\begin{array}{c}9.7 \\
(6.8)\end{array}$ & 0.003 & $\begin{array}{l}9.6 \\
(6.9)\end{array}$ & $\begin{array}{l}12.9 \\
(7.9)\end{array}$ & $<0.001$ \\
\hline DMFT (SD) & $\begin{array}{l}24.9 \\
(6.1)\end{array}$ & $\begin{array}{l}27.1 \\
(4.4)\end{array}$ & 0.001 & $\begin{array}{l}26.6 \\
(5.1)\end{array}$ & $\begin{array}{l}25.1 \\
(5.8)\end{array}$ & 0.02 & $\begin{array}{l}26.0 \\
(5.7)\end{array}$ & $\begin{array}{l}26.5 \\
(5.0)\end{array}$ & 0.95 & $\begin{array}{l}25.8 \\
(5.8)\end{array}$ & $\begin{array}{l}26.5 \\
(4.8)\end{array}$ & 0.40 \\
\hline Decayed (SD) & $\begin{array}{l}2.3 \\
(3.4)\end{array}$ & $\begin{array}{l}1.3 \\
(2.6)\end{array}$ & $<0.001$ & $\begin{array}{l}1,6 \\
(2.8)\end{array}$ & $\begin{array}{l}2.0 \\
(3.4)\end{array}$ & 0.22 & $\begin{array}{l}2.0 \\
(3.2)\end{array}$ & $\begin{array}{c}1.2 \\
(4.5)\end{array}$ & 0.006 & $\begin{array}{l}2.0 \\
(2.8)\end{array}$ & $\begin{array}{r}1.5 \\
(3.2)\end{array}$ & $<0.001$ \\
\hline Filled $(S D)$ & $\begin{array}{l}3.0 \\
(5.4)\end{array}$ & $\begin{array}{l}4.3 \\
(5.5)\end{array}$ & 0.001 & $\begin{array}{l}4.2 \\
(5.9)\end{array}$ & $\begin{array}{l}2.8 \\
(4.2)\end{array}$ & 0.10 & $\begin{array}{l}4.1 \\
(5.9)\end{array}$ & $\begin{array}{l}3.0 \\
(4.5)\end{array}$ & 0.37 & $\begin{array}{c}1.4 \\
(2.6)\end{array}$ & $\begin{array}{l}5.8 \\
(6.5)\end{array}$ & $<0.001$ \\
\hline Missing (SD) & $\begin{array}{l}19.6 \\
(8.4)\end{array}$ & $\begin{array}{l}21.5 \\
(6.8)\end{array}$ & 0.05 & $\begin{array}{l}20.8 \\
(7.8)\end{array}$ & $\begin{array}{l}20.1 \\
(7.1)\end{array}$ & 0.32 & $\begin{array}{l}19.9 \\
(7.8)\end{array}$ & $\begin{array}{l}22.3 \\
(6.8)\end{array}$ & 0.003 & $\begin{array}{l}22.4 \\
(6.9)\end{array}$ & $\begin{array}{l}19.2 \\
(7.9)\end{array}$ & $<0.001$ \\
\hline
\end{tabular}

index and its components, according to city size, in the sample stratified by gender and age. Females living in small cities exhibited more decayed teeth and fewer filled teeth. Younger individuals living in small cities presented more filled teeth, and older individuals living in small cities exhibited lower mean of filled teeth compared to medium and large cities.

\section{DISCUSSION}

Dental caries and periodontal disease have been considered as main determinants for the high occurrence of tooth loss and consequently for the high percentage of edentulism ${ }^{4,14}$, In developing countries like Brazil, tooth loss is associated with the lack of oral health policies aimed at older adults and the elderly population ${ }^{11}$.

Since this study was an exploratory investigation, the obtained results should not be extrapolated to the general population, but only for this study group.

Considering that edentulism is an important indicator of the population's oral health condition ${ }^{4}$, the high prevalence of edentulism found in this study reflects a dissatisfactory condition, which has also been reported in other studies ${ }^{1,12,13}$.This indicates the result of ineffective dental treatments performed along their lives. Therefore, when this population reaches the third age, rehabilitative treatment becomes their only option. Conversely, in places with adequate attention to this population group, satisfactory oral health conditions may be observed, with lower prevalence of edentulism $^{17,19}$.

Some studies have reported that the number of missing teeth was regarded as a negative predictor for the use of dental services. Among adults, edentulism has been considered one of the most important indicators of dental care and conditions $^{21,22}$.

When the prevalence of edentulism observed for individuals aged 65 to 74 years is compared to data from the literature review, a variation of $14 \%$ to $44 \%$ was observed ${ }^{13}$, lower than the results found in the present study. When these results were compared to studies conducted in Brazil and for individuals older than 60 years, the results were quite similar, with institutionalized elderly individuals presenting a percentage of edentulism between $58.1 \%$ and $72 \%$.,14. For noninstitutionalized elderly individuals, the prevalence ranged from $45.5 \%$ to $74 \% \%^{3,18}$. In this study, which also evaluated noninstitutionalized elderly individuals, the percentage of 
edentulism was high. However, the values found were similar to those observed in other Brazilian cities.

With regard to edentulism in the present study, it should be mentioned that many reasons other than dental caries may lead to tooth extraction in this age group, including periodontal disease, trauma, patient preference, and others. However, due to the difficulty to retrieve these data during examination, all missing teeth were considered as missing due to caries. This is an inherent limitation of the DMFT index applied to this age range.

As a result of early extractions, probably due to the lack of access to dental services and care, the elderly population presented a very low mean number of present teeth (3.5). However, when edentulous individuals were excluded from the general sample, the mean number of present teeth was approximately three times larger [11.3] [Table 2], as observed in previous studies ${ }^{9,10}$. In other words, when all individuals were considered for analysis of this variable, the edentulous individuals diluted the results, thus suggesting the inclusion of dentate individuals only when analyzing the mean number of present teeth. Another important point regarding the mean of present teeth is that this mean has been directly associated with the risk of caries onset ${ }^{12}$ as well as quality of life $e^{4,20}$.

In addition, the DMFT index in this population was quite high (Table 2). Nevertheless, these values are in agreement with results from other studies conducted in Brazil ${ }^{3,18}$. International studies commonly exclude edentulous individuals from the DMFT analysis. When this was performed in the present study, there was a decrease in the DMFT value, which is a similar result to that observed in international studies ${ }^{17,19,23}$.

The oral health conditions were analyzed in relation to the sociodemographic variables among dentate elderly individuals (Table 3). With regard to gender (Table 3), males presented lower DMFT, more decayed and fewer filled teeth, suggesting either a lack of access to dental services or a lower search for dental care, as reported by Carneiro, et al. ${ }^{2}$ (2005), who observed a higher percentage of women searching for dental assistance than men. The opposite was reported in a cohort study involving elderly individuals older than 80 years after a 10-year follow-up period, in which the women presented worse oral health conditions than men, with higher percentage of edentulism, fewer intact teeth, higher DMFT index, more restored and fewer decayed teeth compared to the men ${ }^{7}$.

When the oral health conditions were analyzed in relation to the age group (Table 3), differences were verified regarding the mean of present teeth and decayed teeth, with higher rate among younger individuals (65-69 years). Conversely, these elderly individuals presented more missing teeth. This result may be associated to the fact that, the chance of losing natural teeth increases with aging and hence these individuals are expected to present fewer decayed and filled teeth. This condition was also verified by Mack, et al. (2004) ${ }^{10}$. Still according to Table 3, the HDI seemed to be a satisfactory instrument, revealing that, except for the DMFT, all other oral conditions analyzed in this study presented significant differences. Cities with medium HDI presented worse oral conditions, which indicates that people living in cities with higher socioeconomic level presented better oral conditions. 
Fernandes and Peres ${ }^{5}$ (2005) reported that cities with worse socioeconomic indicators exhibited higher rates of tooth extraction, which may be associated with advanced stages of the disease, in which no other therapeutic possibilities were offered.

The number of inhabitants in the city also showed differences in relation to the oral conditions. Individuals living in small-sized cities apparently presented worse oral conditions, since they had more decayed teeth and fewer filled teeth (Table 4). In addition to the first analysis, the city size was compared to the variables gender and age (Table 5). The results presented in Table 5 show that with regard to gender, only for the females, the percentage of decayed teeth was higher for people living in small cities and the percentage of filled teeth was smaller for individuals living in small-sized cities.

\section{CONCLUSION}

Poor oral health conditions were verified in the studied population, as demonstrated by the high percentage of missing teeth and high prevalence of edentulism. It may also be concluded that there is a lack of attention directed to this age group and that the use of specific and thorough dental programs aimed at health promotion and prevention of dental caries, as well as the establishment of public health policies with easy access to this population are necessary to improve oral health conditions in the elderly population.

\section{REFERENCES}

1- Cangussu MCT, Coelho EO, Castellanos-Fernandez RA. Oral health conditions in adults and elderly in Itatiba/SP, Brazil - 2000. [article in Portuguese]. Rev Odontol Unesp. 2001;30:245-56.

2- Carneiro RMV, Silva DD, Sousa MLR, Wada RS. Oral health of institutionalized elderly in the Eastern Zone of São Paulo, Brazil, 1999. [article in Portuguese]. Rep Public Health. 2005;21:1709-16.

3- Colussi CF, Freitas SFT, Calvo MCM. Epidemiological profile of caries and the use and need of prostheses in the elderly population of Biguaçu, Santa Catarina, Brazil. [article in Portuguese]. Rev Bras Epidemiol. 2004;7:8897.

4- Copeland LB, Krall EA, Brown LJ, Garcia RI, Streckfus CF. Predictors of tooth loss in two US adult populations. J Public Health Dent. 2004;64:31-7. 5- Fernandes LS, Peres MA. Association between primary dental care and municipal socioeconomic indicators. [article in Portuguese] Rev Saude Publica. 2005; 39: 930-6.

6- Gaião LR, Almeida MEL, Heukelbachl J. Epidemiology of tooth decay, periodontal diseases, use and need of prostheses in the elderly living in a nursing home in the city of Fortaleza, State of Ceará (Brazil). [article in Portuguese]. Rev Bras Epidemiol. 2005;8:316-23.

7- Hämäläinen P, Meurman JH, Keskinen M, Heikkinen E. Changes in dental status over 10 years in 80-year-old people: a prospective cohort study. Community Dent Oral Epidemiol. 2004;32:374-84.

8- Imazato S, Ikebe K, Nokubi T, Ebisu S, Walls AWG. Prevalence of root caries in a select population of older adults in Japan. J Oral Rehabil. 2006;33:137-43.
9- Kalsbeek H, Truin GJ, Van Rossum GM, Van Rijkom HM, Poorterman JH, Verrips GH. Trends in caries prevalence in Dutch adults between 1983 and 1995. Caries Res. 1998;32:160-5.

10- Mack F, Mojon P, Budtz-Jfrgensen E, Kocher T, Splieth C, Schwahn C, et al. Caries and periodontal disease of the elderly in Pomerania, Germany: results of the Study of Health in Pomerania. Gerodontology. 2004;21:27-36.

11- Mendonça, TC. Dental mutilation: rural workers' concepts of responsibility for tooth loss. [article in Portuguese]. Rep Public Health. 2001;17:1545-7.

12- Nicolau B, Srisilapanan P, Marcenes W. Number of teeth and risk of root caries. Gerodontology. 2000;17:91-6.

13- Petersen PE, Bourgeouis D, Ogawa H, Estupinan-Day S, Ndiaye C. The global burden of oral diseases and risks to oral health. Bull World Health Organ. 2005;83:661-9.

14- Reis SCGB, Higino MASP, Melo HMD, Freire MCM. Oral health status of institutionalized elderly in Goiânia - GO, Brazil, 2003. [article in Portuguese]. Rev Bras Epidemiol. 2005;8:67-73.

15- São Paulo. Fundação Sistema Estadual de Análise de Dados - SEADE. Condições de vida - índice de desenvolvimento humano do estado de São Paulo [text on the Internet]. São Paulo: Fundação SEADE; 2006 [cited 2008 Nov 18]. Available from: <http://www.seade.gov.br.>

16- São Paulo. Secretaria Estadual de Saúde de São Paulo. Saúde bucal. Levantamento epidemiológico [text on the Internet]. São Paulo: Secretaria da Saúde; 1998. [cited 2008 Nov 18]. Available from: <http:// www.saude.sp.gov.br/saude_bucal/html/saude_bucal_est_epide.html>

17- Shah N, Sundaran KR. Impact of socio-demografic variables, oral hygiene practices, oral habits and diet on dental caries experience of Indian elderly: a community-based study. Gerodontology. 2004;21:43-50.

18- Silva DD, Sousa MLR, Wada RS. Self-perception and oral health conditions in an elderly population. [article in Portuguese]. Rep Public Health. 2005;21:1251-9.

19- Skudutyte R, Alesejuniene J, Eriksen HM. Dental Caries in adults Lithuanians. Acta Odontol Scand 2000;58:143-7.

20- Steele JG, Sanders AE, Slade GD, Allen PF, Lahti S, Nuttall AJ, et al. How do age and tooth loss affect oral health impacts and quality of life? A study comparing two national samples. Community Dent Oral Epidemiol. 2004;32:107-14.

21- Suominen-Taipale AL, Alanen P, Helenius H, Nordblad A, Uutela A. Edentulism among Finnish adults of working age, 1978-1997. Community Dent Oral Epidemiol. 1999;27: 353-65.

22- Suominen-Taipale AL, Widstrom E, Alanen P, Uutela A. Trends in selfreported use of dental services among Finnish adults during two decades. Community Dent Health. 2000;17:31-7.

23- The Spanish Geriatric Oral Health Research Group. Oral health issues of Spanish adults aged 65 and over. Int Dent J. 2001;51:228-34.

24- Varenne B, Petersen PE, Ouattara S. Oral health status of children and adults in urban and rural areas of Burkina Faso Africa. Int Dent J. 2004;54:83-

25- World Health Organization. Oral Health Surveys: basic methods. $3^{\text {rd }}$ Ed. Geneva: World Health Organization; 1987.

26- World Health Organization. Oral Health Surveys: basic methods. $4^{\text {th }}$ Ed. Geneva: World Health Organization; 1997. 